Original article

\title{
INVESTIGATIONS ON TETRACYCLINE RESISTANCE IN COMMENSAL ESCHERICHIA COLI ISOLATES FROM SWINE
}

\author{
V. URUMOVA \\ Department of Veterinary Microbiology, Infectious and Parasitic Diseases, \\ Faculty of Veterinary Medicine, Trakia University, Stara Zagora, Bulgaria
}

\begin{abstract}
Summary
Urumova, V., 2016. Investigations on tetracycline resistance in commensal Escherichia coli isolates from swine. Bulg. J. Vet. Med., 19, No 3, 179-188.

The distribution of tetracycline resistance in commensal E. coli strains, isolated from pigs at different stages of production system was investigated in four Bulgarian swine farms. The prevalence of antibiotic resistance and particularly tetracycline resistance, as well as two tetracycline resistance genes were evaluated in Escherichia coli isolates from swine faeces and manure lagoons. A total of $109 \mathrm{E}$. coli isolates from 116 faecal samples and 7 samples from manure lagoons were tested by disk diffusion method to determine resistance patterns to 10 antimicrobial agents. Tetracycline resistance was determined by disk diffusion method, micro-broth dilution method and qPCR. About $83 \%$ of the $E$. coli isolates from swine were resistant to one or more antimicrobial agents, respectively. The highest resistance observed in swine $E$. coli isolates was that to tetracycline (75.2\%). The resistant $E$. coli isolates to tetracycline were examined for the presence of tet genes: tet (A) and tet (B). The most commonly identified tet gene was tet (A), which was found in $96.4 \%$ of swine and manure lagoon isolates.
\end{abstract}

Key words: commensal Escherichia coli, pig manure, tetracycline resistance

\section{INTRODUCTION}

Animal production farms are an important source for spread of genes coding for resistance to antibiotics in the environment. Consequently to the wide use of antibiotics in livestock production for both prevention and therapy, an increasing prevalence of various resistance genes in the environment is reported (Chee-Sandford et al., 2001; Kim et al., 2011; Li et al., 2013). According to Esiobu et al. (2002), there is a relationship between the use of antibiotics in pig farms and the occurrence of resistance genes in bacteria from manure, manure lagoons, as well as soil bacteria. On the other hand, the presence of resistant bacteria among the commensal microflora in organic cattle and pig farms, where the use of chemotherapeutics is limited, is also discussed (Hoyle et al., 2006; Jindal et al., 2012). This probably implies the existence of factors other than the selective pressure of chemotherapeutics to influence these processes. 
Tetracyclines are often used in swine for therapy of bacterial enterites, gynaecological and respiratory infections, atrophic rhinitis etc. The variety of tetracycline resistance genes is commonly seen among both Gram-positive and Gram-negative bacteria, and their spread also refers to some specific environmental locations such as manure lagoons and underground waters (Callens et al., 2012; Jensen et al., 2012). Therefore, the tetracycline resistance could be used as a key factor in the monitoring of resistance genes in indicator porcine coli bacteria in studies on manure lagoons, underground waters and soils.

The horizontal transfer of resistance genes and in particular, tetracycline resistance genes is the main mechanism of their rapid spread among various bacterial species (Aminov et al., 2001; Chopra \& Roberts, 2001). The manure from pig farms used for fertilisation of cultivable land, and faeces-contaminated underground waters could be regarded as critical zones for horizontal transfer of resistance genes and opportunistic bacterial species (Chee-Sanford et al., 2009). On the other side, the commensal intestinal microflora of domestic livestock is the main reservoir for exchange of genetic resistance determinants and that is why they are used for evaluation of antibiotic resistance levels in a number of European monitoring programmes along with zoonotic bacterial agents (WHO, 1997; Witte, 2000; Blake et al., 2003; Lappierre et al., 2008).

\section{MATERIALS AND METHODS}

\section{Farms and antibiotic use policy}

Farm - I

Total number of sows -1100 ;

Number of manure lagoons - 1;

Antibiotic use policy: Wide use of colistin sulfate for metaphylaxis of post weaning enterites, etiologically associated with EHEC and ETEC in growing pigs. Wide use of amoxicillin and ceftiofur in various clinical forms of $S$. suis infection in suckling and growing pigs. The farm is free of dysentery and colonic spirochaetosis, which does not require the application of tiamulins and tetracyclines.

Farm - II

Total number of sows - 1180;

Number of manure lagoons - 1;

Antibiotic use policy: Wide use of colistin sulfate for metaphylaxis of post weaning enterites, etiologically associated with EHEC and ETEC in growing pigs. Due to the stationary nature of swine dysentery and proliferative enteropathy, a continuous use of tiamulin preparations and tetracyclines as well as tylosin is noted. Lincomycin and lincospectin are also commonly used.

Farm - III

Total number of sows -4000 ;

Number of manure lagoons - 1 ;

Antibiotic use policy: Wide use of ceftiofur for metaphylaxis of streptococcal infections in suckling and growing pigs, as well as administration of tetracyclines, lincomycin and amoxicillin.

Farm - IV

Total number of sows - 1500;

Number of manure lagoons - 1;

Antibiotic use policy: Wide use of ceftiofur for metaphylaxis of streptococcal infections in suckling and growing pigs. Due to the stationary nature of swine dysentery and colonic spirochaetosis, lincospectin, tiamulins often combined with oxy- or chlortetracycline are used.

\section{Collection of the samples}

Between December 2013 and May 2014, 120 faecal swab samples were collected 
from different age groups of pigs (suckling, weaned, finisher) as well as from manure lagoons at farms. Faecal swabs were transported in Stuart Transport Medium (BD, USA) at low temperature within 18-24 hours. The materials for microbiological examination from each of manure lagoons were collected from the liquid phase at a depth of $20-40 \mathrm{~cm}$. The total sample volume consisted of 3 separate samples with equal volume, which were transported in sterile containers at low temperature.

\section{Culturing and identification of E. coli isolates}

Swab and lagoon samples were cultured on Mc Conkey agar (Emapol, Poland) at $37^{\circ} \mathrm{C}$ for 24 hours. Lactose-positive colonies were sub-cultured onto triple-sugar iron (TSI) agar (BD, USA) and submitted to preliminary biochemical typing via citrate utilisation, methyl red, Vogues Proskauer and indole production tests. The identification of strains was performed with kits for non-fermenting and enteric bacteria (BD, USA) and the semiautomated Crystal BBL identification system.

Determination of the sensitivity of E. coli isolates to antibiotics

The sensitivity of $E$. coli isolates to 10 chemotherapeutics was evaluated by the disk diffusion method as per CLSI (2010), using Muller-Hinton agar (Emapol, Poland) and antibiotic disks (Emapol, Poland), loaded as followed: amoxicillin (10 $\mu \mathrm{g})$, cephalotin $(30 \mu \mathrm{g})$, ceftazidime $(10$ $\mu \mathrm{g})$, cefotaxime $(30 \mu \mathrm{g})$, gentamicin $(10$ $\mu \mathrm{g})$, streptomycin $(10 \mu \mathrm{g})$, spectinomycin $(25 \mu \mathrm{g})$, tetracycline $(30 \mu \mathrm{g})$, enrofloxacin $(5 \mu \mathrm{g})$, sulfamethoxazole $(25 \mu \mathrm{g})$. To determine the sensitivity of isolates to beta lactams, amoxicillin, cephalotin, cefo- taxime and ceftazidime, the synergic amoxicillin/clavulanic acid $(20 / 10 \mu \mathrm{g})$ test was used. Antibiogrammes were controlled with a reference strain Escherichia coli ATTC 25922.

The tetracycline MIC were determined with micro-broth dilution test and cationadjusted Muller-Hinton broth (Emapol, Poland), by preparation of doubling dilutions of tetracycline within $0.25-32$ $\mu \mathrm{g} / \mathrm{mL}$. The tetracycline resistance breakpoint was $\geq 16 \mu \mathrm{g} / \mathrm{mL}$.

Determination of tetracycline resistance genes in E. coli strains

DNA extraction. For DNA extraction, 24hour cultures incubated at $37{ }^{\circ} \mathrm{C}$, respectively 3-4 colonies on McConkey agar were suspended in $100 \mu \mathrm{L}$ sterile distilled water free of inhibitors for molecular diagnostics (Qiagen, Germany). The DNA extraction kit DNeasy Blood Tissue Kit (Qiagen, Germany) was carried out.

Amplification method. To determine the tetracycline resistance genes, Microbial DNA qPCR Assay, tet (A) and tet (B) (Qiagen, Germany) were used. The qPCR amplification was done with Stratagene Mx3000P instrument. The thermocycler protocol consisted of: initial PCR activation $10 \mathrm{~min}, 95^{\circ} \mathrm{C}, 1$ cycle, 2-step cycling - denaturation $\left(15 \mathrm{~s}, 95{ }^{\circ} \mathrm{C}\right)$, annealing and extension $\left(2 \mathrm{~min}, 60^{\circ} \mathrm{C} \times 40\right.$ cycles $)$. The results were interpreted according to manufacturer's instructions (negative control signal at $\mathrm{C}_{\mathrm{T}}<35$ and $\mathrm{C}_{\mathrm{T}}=22 \pm 2$ for internal positive PCR control, PPC).

\section{RESULTS}

The total number of E. coli isolates from examined swab samples was 102 , and from manure lagoons -7 .

Data about the presence of resistant $E$. coli strains isolated from the different 
categories of pigs and lagoons at the four farms are summarised in Table 1. The highest number of resistant strains to the 10 tested chemotherapeutics was found in the groups of weaned pigs $-40.5 \%$, followed by finisher pigs with $23.8 \%$ and the neonatal group with $15.5 \%$. The total prevalence of resistant $E$. coli isolates for the four farms was $83.4 \%$.
The resistance patterns of $E$. coli strains in the different age groups at the farms are presented in Table 2. A total of 18 resistance patterns were observed. The Ax S SPT T SMZ resistance pattern exhibited the highest percentage $(28.4 \%)$ of multi-resistant strains, followed by the Ax S SPT T with 19.3\%. Tetracycline belonged to the 15 identified resistance

Table 1. Prevalence of resistance to at least one of 10 tested antimicrobials among faecal E. coli from pigs on 4 farrow-to-finish farms

\begin{tabular}{lcc}
\hline Source & $\begin{array}{c}\text { Prevalence of resistance } \\
(\text { number } / \%)\end{array}$ & $95 \%$ confidence limits \\
\hline Suckling pigs $(\mathrm{n}=24)$ & $17 / 15.5 \%$ & $9.0 \div 22.4$ \\
Weaned pigs $(\mathrm{n}=49)$ & $44 / 40.5 \%$ & $31.4 \div 49.9$ \\
Finisher pigs $(\mathrm{n}=29)$ & $26 / 23.8 \%$ & $16.1 \div 31.9$ \\
Manure lagoon $(\mathrm{n}=7)$ & $4 / 3.7 \%$ & $0.9 \div 8.0$ \\
\hline Total $(\mathrm{n}=109)$ & $91 / 83.4 \%$ & $75.3 \div 89.4$ \\
\hline
\end{tabular}

Table 2. Patterns of resistance to 10 antimicrobials among $E$. coli from 4 farrow-to-finish farms $(\mathrm{n}=91)$

\begin{tabular}{lcc}
\hline Patterns of resistance to & $\begin{array}{c}\text { Number of } \\
\text { resistant isolates }\end{array}$ & $\begin{array}{c}\text { Percentage of } \\
\text { resistant isolates }\end{array}$ \\
\hline Ax KF S SPT T Enr & 1 & 1.1 \\
Ax KF GN S SPT T & 2 & 2.3 \\
Ax GN S SPT T SMZ & 4 & 4.5 \\
Ax S SPT T Enr & 1 & 1.1 \\
Ax KF S SPT T & 4 & 4.5 \\
Ax GN S SPT T & 2 & 2.3 \\
Ax KF GN S T & 5 & 1.1 \\
GN S SPT T SMZ & 2 & 2.3 \\
Ax S SPT T SMZ & 25 & 28.4 \\
Ax KF T SMZ & 1 & 1.1 \\
Ax KF T & 4 & 4.5 \\
Ax S SPT SMZ & 4 & 4.5 \\
Ax S SPT T & 17 & 19.3 \\
GN S SPT T & 3 & 3.4 \\
Ax KF & 1 & 1.1 \\
S SPT T & 4 & 4.5 \\
GN S SPT & 4 & 4.5 \\
T & 7 & 7.9 \\
\hline
\end{tabular}

Ax-amoxicillin; KF-cephalotin; CAZ-ceftazidime; CTX-cefotaxime; GN-gentamicin; S-streptomycin; SPT-spectinomycin; T-tetracycline; Enr-enrofloxacin; SMZ-sulfamethoxazole. 


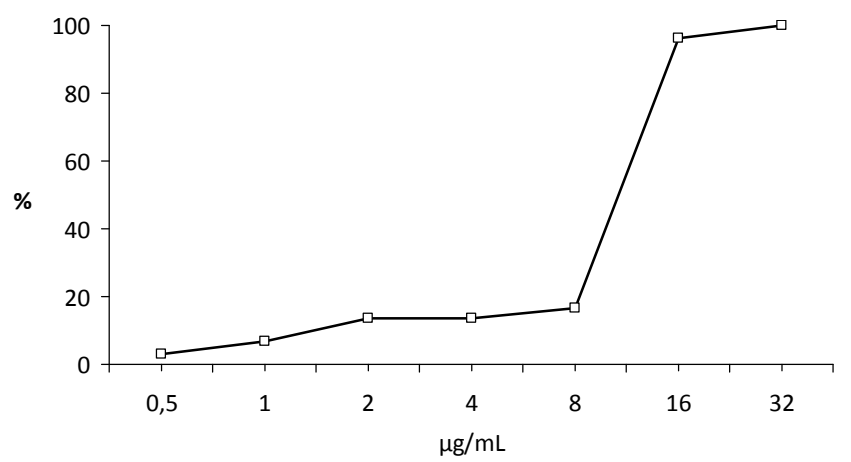

Fig. 1. MIC of tetracycline in E. coli isolates from pigs.

Table 3. Detected resistance genes in phenotypically tetracycline resistant porcine $E$. coli $(\mathrm{n}=91)$

\begin{tabular}{|c|c|c|c|c|c|c|}
\hline \multirow[b]{2}{*}{ Genotype } & \multicolumn{5}{|c|}{ Number/percentage } & \multirow[b]{2}{*}{ CL 95\% } \\
\hline & $\begin{array}{l}\text { Suckling } \\
\text { pigs } \\
(\mathrm{n}=24)\end{array}$ & $\begin{array}{c}\text { Weaned } \\
\text { pigs } \\
(n=49)\end{array}$ & $\begin{array}{c}\text { Finishers } \\
(n=29)\end{array}$ & $\begin{array}{l}\text { Manure la- } \\
\text { goon }(n=7)\end{array}$ & $\begin{array}{c}\text { Total } \\
(n=109)\end{array}$ & \\
\hline $\begin{array}{l}\text { Tetracycline } \\
\text { resistance }\end{array}$ & $17 / 15.5 \%$ & $44 / 40.5 \%$ & $26 / 23.8 \%$ & $4 / 3.7 \%$ & $91 / 83.4 \%$ & $75.3 \div 89.4$ \\
\hline tet $(\mathrm{A})$ & $14 / 12.8 \%$ & $41 / 37.6 \%$ & $21 / 19.2 \%$ & $3 / 2.7 \%$ & $79 / 72.4 \%$ & $63.7 \div 80.3$ \\
\hline tet $(\mathrm{B})$ & - & - & $2 / 1.8 \%$ & $1 / 0.9 \%$ & $3 / 2.7 \%$ & $0.5 \div 6.5$ \\
\hline tet $(\mathrm{A})$ tet $(\mathrm{B})$ & - & - & - & - & - & \\
\hline
\end{tabular}

$\mathrm{CL}$ - confidence limits.

patterns; resistance to tetracycline only was demonstrated by $7.9 \%$ of isolates.

The cumulative curve of tetracycline on the basis of detected MICs of tetracycline in tested strains (Fig. 1) showed that the $\mathrm{MIC}_{90}$ value was $16 \mu \mathrm{g} / \mathrm{mL}$, and two of resistant isolates had MICs of 32 $\mu \mathrm{g} / \mathrm{mL}$.

The occurrence of efflux genes tet (A) and tet (B) in E. coli strains isolated from pigs at different ages and from manure lagoons at surveyed farms are presented in Table 3. The prevalence of gene tet (A) among strains isolated from pigs and lagoons was $72.4 \%$. Two of $E$. coli strains from the finisher pigs group $(1.8 \%)$ and 1 isolate from the lagoons $(0.9 \%)$ possessed tet (B). None of tetracycline-resistant strains in this study exhibited the combination of tet $(\mathrm{A})$ and tet $(\mathrm{B})$.

\section{DISCUSSION}

Literature data with information about the role of manure utilisation and the spread of resistance genes in animal farm environment, the soil and underground waters are few. Therefore, studies reporting such data would be useful allowing a more objective evaluation of the risk from using chemotherapeutics in animal production systems. From this point of view, an important fact which sometimes precludes the considerable difference in reports from European and North America researchers is that in the USA and Canada, 
chemotherapeutics including tetracyclines are still used not only for therapy but also as growth promoters.

Barton (2000) and Teuber (2001) affirm that in animal practice, about $50 \%$ of chemotherapeutics are used at subtherapeutic doses for prophylaxis and as growth promoters. Data of the American Health Institute from 2001 place tetracyclines on the leading place as their use in medicine is concerned: 3,239 tonnes annually, followed by macrolides, lincosamides, polypeptides, streptogramins and cephalosporins, 1,937 tonnes per year. In Denmark, Aarestrup (2005) determined tetracyclines as the most commonly used antibiotics in the animal practice. In 2009, according to data of European Medicines Agency (2011) and Grave et al. (2012), the share of tetracyclines in sales of antibiotics for use in animals was $40 \%$. These facts certainly uncover the risk posed by the high selective pressure on the spread of resistance to chemotherapeutics in men, animals and the environment. In addition, the great diversity of bacterial species isolated from the manure of pig farms 60 belonging to 28 genera, acknowledged to possess tetracycline resistance and plasmid factors for transfer of genetic determinants, should also be taken into consideration (Binh et al., 2008).

The results from the European project "Antibiotic resistance in bacteria of animal origin -II" (ARBAO-II) from 2004, regarding the sensitivity to tetracycline of porcine commensal $E$. coli strains indicate a high percentage of resistance in a number of EC countries: $95.6 \%$ in Poland, $86.0 \%$ in Great Britain, $81.0 \%$ in France, $63.9 \%$ in Finland, $58.1 \%$ in Austria, $43.8 \%$ in Denmark and $31.9 \%$ in the Netherlands (Hendriksen et al., 2008). In Bulgaria, such long-term monitoring studies on the resistance to antibiotics in commensal enteric bacteria have not been carried out and our data obtained from four large pig farms in the country, indicating a high prevalence of resistance (83.4\%) among porcine E. coli commensals, could be commented in the light of aforementioned data.

Akwar et al. (2008) performed an analysis of the high prevalence of tetracycline resistance $(89.5 \%)$ in E. coli strains in healthy weaned pigs, which is explained with the fact that this technological group is highly sensitive to bacterial infections and thus, more frequently subjected to therapeutic antibiotic pressure than finisher pigs. The phenotypic as well as genotypic expression of tetracycline resistance shown in this study is also with highest percentage $(40.5 \% ; 37.6 \%)$ in $E$. coli strains isolated from weaned pigs.

Blake et al. (2003) discussed the presence of tet (B) and high MIC in E. coli strains from pigs with multi-resistance profiles including ampicillin, streptomycin and chloramphenicol. According to the researchers, tet (A) and tet (C) are detected in strains with lower resistance levels as determined by MIC, moreover, they believe that these genes are not present in isolates from intensive pig farms. They have neither found more than one gene in tetracycline-resistant $E$. coli strains unlike Marshall et al. (1983) and Lee et al. (2000), which in their opinion had not any significant effect on MICs. Lanz et al. (2003) report a high occurrence of $87 \%$ of tet $(\mathrm{A})$ in porcine clinical tetracycline-resistant $E$. coli strains. Sengelǿv et al. (2003) also discussed the dominance of tet (A) in E. coli strains from healthy and diseased pigs, cattle and poultry $(71 \%)$ and did not establish any difference in the prevalence of resistance genes in commensal and clinical strains. The association of high MIC to tetracyc- 
line and occurrence of tet (B) are also commented by Lee et al. (2000) and Sunde et al. (1998). Lee et al. (1993) demonstrated MIC $>128 \mu \mathrm{g} / \mathrm{mL}$ in $93 \%$ of resistant $E$. coli bacteria from pigs with tet (B). In the USA, Bryan et al. (2004) established a high level of tetracycline resistance of $78 \%$ in commensal coli bacteria from pigs, at the background of high MIC $-233 \mu \mathrm{g} / \mathrm{mL}$, the genotype of which was related to higher percentage of tet (B) than of tet (A): $63 \%$ vs 35\% respectively. In $30 \%$ of isolates the authors observed more than one gene coding for tetracycline resistance. The established $\mathrm{MIC}_{90}$ to tetracycline was $16 \mu \mathrm{g} / \mathrm{mL}$, in $E$. coli isolates from the different age groups and manure lagoons, and the value is comparable to that commented by Blake et al. (2003), with the only difference that our survey was performed in intensive pig farms.

In the Republic of Korea, Cho \& Kim (2008) discussed the high occurrence $(90.3 \%)$ of tetracycline resistance in commensal $E$. coli strains isolated from pigs with involvement of the tet (A) genotype in $98.2 \%$ of cases. In Canada, Kozac et al. (2009) also observed a high tetracycline resistance of $83 \%$ in commensal porcine $E$. coli strains, although the more common genotypic expression was that of tet (B) $-59 \%$. The monitoring of commensal E. coli strains from pigs carrying the tetracycline resistance genes conducted by Schwaiger et al. (2010) has shown a predominance with $>55 \%$ of tet (A) and the presence of a single gene only in $88 \%$ of cases.

In our study, the genotypic expression of tetracycline resistance was characterised with dominance of tet (A) in $72.4 \%$ of resistant isolates, so our results corresponded the best to those of Sengelǿv et al. (2003) and Cho \& Kim (2008).
Barkovskii \& Bridges (2012) found out preponderance of genes determining the mechanism of ribosomal protection tet (M) as well as efflux genes. The authors outlined the close association between resistance genes from animal faeces and those in lagoons, and concluded that lagoons were an important source of resistance genes in the farm environment. They discussed the thesis that tet (B) could be determined as indicator gene in both faeces and manure lagoons at farms utilising chlortetracycline as growth promoter. The more general analysis of the three studied farms from the cited study however allowed affirming that the diversity of genetic determinants at pig farms was not dependent on the use of tetracycline. In $E$. coli isolates from lagoons and other facilities in the proximity of pig farms, Graves et al. (2011) established a high incidence of $91.3 \%$ of tet (A) and tet (B). With respect to the spread of genetic determinants of resistance in $E$. coli isolates from the lagoons of studied farms, we proved a higher occurrence of tet (A) $2.7 \%$ than of tet $(\mathrm{B})-0.9 \%$. Analysing the data about manure lagoons isolates, it should be said that first, they were few and second, that four of them exhibited tetracycline resistance.

\section{CONCLUSION}

Antimicrobial resistance of commensal $E$. coli is of public health significance, particularly the quick selection of multidrugresistant populations in different group of animals. The horizontal gene transfer of commensal $E$. coli can be associated to co-resistance and may be transferred to pathogenic strains of Enterobacteriaceae spp. There are several examples of humans colonised by resistant commensal $E$. coli from food animals and there are pos- 
sibilities for limiting therapeutic options. That is why the monitoring of antimicrobial resistances in commensal $E$. coli from food animals and the farm environment is important for real trends assessment.

\section{REFERENCES}

Aarestrup, F. M., 2005. Veterinary drug usage and antimicrobial resistance in bacteria of animal origin. Basic \& Clinical Pharmacology \& Toxicology, 96, 271-281.

Akwar, H. T., C. Poppe, J. Wilson, R. J. ReidSmith, M. Dyck, J. Waddington, D. Shang \& S. A. McEwen, 2008. Prevalence and patterns of antimicrobial resistance of fecal Escherichia coli among pigs on 47 farrowto-finish farms with different in-feed medication policies in Ontario and British Columbia. Canadian Journal of Veterinary Research, 72, 195-201.

Aminov, R. I., N. Garrigues-Jeanjean \& R. I. Mackie, 2001. Molecular ecology of tetracycline resistance: Development and validation of primers for detection of tetracycline resistance genes encoding ribosomal protection proteins. Applied Environmental Microbiology, 67, 22-32.

Barkovskii, A. L. \& C. Bridges, 2012. Persistence and profiles of tetracycline resistance genes in swine farms and impact of operational practices on their occurrence in farms' vicinities. Water, Air, \& Soil Pollution, 223, 49-62.

Barton, M. D., 2000. Antibiotic use in animal feed and its impact on human health. $\mathrm{Nu}$ trition Research Review, 13, 279-299.

Binh, C. T., H. Heuer, M. Kaupenjohann \& K. Smalla, 2008. Piggery manure used for soil fertilization is a reservoir for transferable antibiotic resistance plasmids. FEMS Microbiology Ecology, 66, 25-37.

Blake, D. P., R. W. Humphry, K. P. Scott, K. Hillman, D. R. Fenlon \& J. C. Low, 2003. Influence of tetracycline exposure on tetracycline resistance and the carriage of tetracycline resistance genes within commen- sal Escherichia coli populations. Journal of Applied Microbiology, 94, 1087-1097.

Bryan, A., N. Shapir \& M. Sadowski, 2004. Frequency and distribution of tetracycline resistance genes in genetically diverse, nonselected, and nonclinical Escherichia coli strains isolated from diverse human and animal sources. Applied Environmental Microbiology, 70, 2503-2507.

Callens, B., D. Persoons, D. Maes, M. Laanen, M. Postma, F. Boyen, F. Haesebrouck, P. Butaye, B. Catry \& J. Dewulf, 2012. Prophylactic and metaphylactic antimicrobial use in Belgian fattening pig herds. Preventive Veterinary Medicine, 106, 53-62.

Chee-Sanford, J. C., R. I. Aminov \& I. Krapac, 2001. Occurrence and diversity of tetracycline resistance genes lagoons and groundwater underlying two swine production facilities. Applied Environmental Microbiology, 67, 1494-1502.

Chee-Sanford, J. C., R. I. Mackie, S. Koike, I. G. Krapac, Y. F. Lin, A. C.Yannarell, S. Maxwell \& R. I. Aminov. 2009. Fate and transport of antibiotic residues and antibiotic resistance genes following land application of manure waste. Journal of Environmental Quality, 38, 1086-1108.

Cho, J. K. \& K. S. Kim, 2008. Antimicrobial resistance and distribution of tetracycline resistance genes of Escherichia coli isolated from human and livestock in slaughterhouse. Korean Journal of Veterinary Public Health, 32, 213-223.

Chopra, I. \& M. Roberts, 2001. Tetracycline antibiotics: Mode of action, applications, molecular biology, and epidemiology of bacterial resistance. Microbiology and Molecular Biology Reviews, 65, 232-260.

CLSI, 2010. Clinical and Laboratory Standards Institute, Performance Standards for Antimicrobial Susceptibility Testing; Twentieth Information Supplement. CLSI Document M100-S20, Clinical and Laboratory Standards Institute, Wayne, PA.

Esiobu, N., L. Armenta \& J. Ike, 2002. Antibiotic resistance in soil and water environ- 
ments. International Journal of Environmental Health Research, 12, 133-144.

European Medicines Agency, 2011. Trends in the sales of veterinary antimicrobial agents in nine European countries (2005-2009). EMA/238630/2011. http://www.ema.europa.eu/docs/en_GB/document_library/Report/2011/09/WC500112309.pdf (Date last accessed 28 March 2016).

Grave, K., C. Greco, M. K. Kvaale, J. T. Edo, D. Mackay, A. Muller \& G. Moulin, 2012. Sales of antimicrobial agents in nine European countries during 2005-09. Trends and patterns. Journal of Antimicrobial Chemotherapy, 67, 3001-3008.

Graves, A. K., L. Liwimbi, D. W. Israel, E. van Heugten, B. Robinson, C. W. Cahoon \& J. F. Lubbers, 2011. Distribution of ten antibiotic resistance genes in E. coli isolates from swine manure, lagoon effluent and soil collected from a lagoon waste application field. Folia Microbiology, 56, 131-137.

Hendriksen, R. S., D. J. Mevius, A. Schroeter, C.Teale, E. Jouy, P. Butaye, A. Franco, A.Utinane, A. Amado, M. Moreno, C. Greko, K. C. Stärk Berghold, A.-L. Myllyniemi, A. Horzowski, M. Sunde \& F. M. Aarestrup, 2008. Occurrence of antimicrobial resistance among bacterial pathogens and indicator bacteria in pigs in different European countries from year 2002 2004; the ARBAO-II study. Acta Veterinaria Scandinavica, 50, 19. doi:10. 1186/1751-0147-50-19.

Hoyle, D. V., H. C. Davison, H. I. Knight, C. M. Yates, O. Dobey \& G. I. Gunn, 2006. Molecular characterization of bovine fecal Escherichia coli shows persistence of defined ampicillin resistant strains and the presence of class 1 integrons on an organic beef farm. Veterinary Microbiology, 115 , 250-257.

Jensen, V. F., H. D. Emborg \& F. M. Aarestrup, 2012. Indications and patterns of therapeutic use of antimicrobial agents in the Danish pig production from 2002 to 2008. Journal of Veterinary Pharmacology and Therapeutics, 35, 33-46.
Jindal, A., S. Kocherginskaya, A. Mehboob, R. I. Mackie, L. Raskin \& J. L. Zilles, 2006. Antimicrobial use and resistance in swine waste treatment system. Applied Environmental Microbiology, 72, 7813-7820.

Kim, K. R., G. Owens, S. I. Known, K. H. So \& D. B. Lee, 2011. Occurrence and environmental fate of veterinary antibiotics in the terrestrial environment. Water, Air, \& Soil Pollution, 214, 163-174.

Kozac, G., P. Boerlin, N. Janesco, R. J. ReidSmith \& C. Jardine, 2009. Antimicrobial resistance in Escherichia coli isolates from swine and wild small mammals in the proximity of swine farms and in natural environments in Ontario, Canada. Applied Environmental Microbiology, 75, 559-566.

Lanz, R., P. Kuhnert \& P. Boerlin, 2003. Antimicrobial resistance and resistance gene determinants in clinical Escherichia coli from different animal species in Switzerland. Veterinary Microbiology, 91, 73-84.

Lapierre, L., J. Cornejo, C. Borie, C. Toro \& B. San Martín, 2008. Genetic characterization of antibiotic resistance genes linked to class 1 and class 2 integrons in commensal strains of Escherichia coli isolated from poultry and swine. Microbial Drug Resistance, 14, 265-272.

Lee, A., W. Mao, M. S. Warren, A. Mistry, K. Hoshino, R. Okumura, H. Ishida \& O. Lomovskaya, 2000. Interplay between efflux pumps may provide either additive or multiplicative effects on drug resistance. Journal of Bacteriology, 182, 3142-3150.

Lee, C., B. E. Langlois \& K. A. Dawson. 1993. Detection of tetracycline resistance determinants in pig isolates from three herds with different histories of antimicrobial agent exposure. Applied Environmental Microbiology, 59, 1467-1472.

Li, Y., X. Zhang, W. Li, X. Lu \& B. Liu, 2013. The residues and environmental risks of multiple veterinary antibiotics in animal feces. Environmental Monitoring \& Assessment, 185, 2211-2220.

Marshall, B., C. Tachibana \& S. B. Levy, 1983. Frequency of tetracycline resistance 
determinant classes among lactose-fermenting coliforms. Antimicrobial Agents and Chemotherapy, 24, 835-840.

Sengelǿv, G., B. Halling -Sǿrensen \& F.Aarestrup, 2003. Susceptibility of Escherichia coli and Enterococcus faecium isolated from pigs and broiler chickens to tetracycline degradation products and distribution of tetracycline resistance determinants in E. coli from food animals. Veterinary Microbiology, 95, 91-101.

Schwaiger, K., C. Hölzel \& J. Bauer, 2010. Resistance gene patterns of tetracycline resistance Escherichia coli of human and porcine origin. Veterinary Microbiology, 142, 329-336.

Sunde, M., K. Fossum, A. Solberg \& H. Sǿrum, 1998. Antibiotic resistance in $E s$ cherichia coli of the normal intestinal flora of swine. Microbial Drug Resistance, 4, 289-299.

Teuber, M., 2001. Veterinary use and antibiotic resistance. Current Opinion in Microbiology, 4, 493-499.

WHO, 1997. The medical impact of antimicrobial use in food animals. Report of a WHO Meeting. Berlin, Germany, 13-17 October. WHO/EMC/ZOO/97, WHO, Geneva http://apps.who.int/iris/bitstream/
10665/64439/1/WHO EMC ZOO 97.4.p df (Date last accessed 28 March 2016).

Witte, W., 2000. Ecological impact of antibiotic use in animals on different complex microflora: Environment. International Journal of Antimicrobial Agents, 14, 321-325.

Paper received 11.01.2016; accepted for publication 26.02.2016

\section{Correspondence:}

Assoc. Prof. Valentina Urumova Department of Veterinary Microbiology, Infectious and Parasitic Diseases Faculty of Veterinary Medicine, Trakia University, 6000 Stara Zagora, Bulgaria e-mail: valentina_62@abv.bg 